\title{
Trends in life expectancy among medical aid beneficiaries and National Health Insurance beneficiaries in Korea between 2004 and 2017
}

\author{
Jinwook Bahk', Hee-Yeon Kang ${ }^{2}$ and Young-Ho Khang ${ }^{2,3^{*}}$ (D)
}

\begin{abstract}
Background: Medical Aid beneficiaries in Korea are more likely to have poor health status and to receive insufficient healthcare services, but their life expectancy has not been compared with that of National Health Insurance beneficiaries.

Methods: We used the National Health Information Database in Korea to obtain aggregate data on the numbers of population and deaths according to calendar year (2004 to 2017), sex, age group, and insurance eligibility (Medical Aid or National Health Insurance). Between 2004 and 2017, a summed total of 697,503,634 subjects (combining numbers of subjects for 14 years) and 3,536,778 deaths, including 22,417,216 Medical Aid beneficiaries and 499,604 associated deaths, were used to construct annual abridged life tables.

Results: In 2017, the life expectancy of Medical Aid beneficiaries was 70.9 years, while that of National Health Insurance beneficiaries was 83.7 years. Between 2004 and 2017, life expectancy for Medical Aid beneficiaries increased by 8.7 years in men and 6.1 years in women, while life expectancy for National Health Insurance beneficiaries increased by 5.2 years in men and 4.5 years in women. The life expectancy difference between National Health Insurance beneficiaries and Medical Aid beneficiaries was especially great among men across all study periods. The life expectancy difference was 15.8 years for men and 8.9 years for women in 2017.

Conclusions: The life expectancy of Medical Aid beneficiaries was shorter than that of National Health Insurance beneficiaries. The government should implement policies to deliver more adequate health care to Medical Aid beneficiaries.
\end{abstract}

Keywords: Life expectancy, Medical aid, National Health Insurance, Republic of Korea

\section{Background}

In Republic of Korea (hereafter 'Korea'), the Medical Aid system is a public assistance program that provides healthcare benefits to low-income families, such as those who are eligible through the National Basic Living Security Act. Medical Aid beneficiaries accounted for $2.8 \%$ of all Koreans in 2017, while all other Koreans (97.2\%) were beneficiaries of National Health Insurance

\footnotetext{
* Correspondence: yhkhang@snu.ac.kr

${ }^{2}$ Department of Health Policy and Management, Seoul National University College of Medicine, 103 Daehak-ro, Jongno-gu, Seoul 03080, South Korea ${ }^{3}$ Institute of Health Policy and Management, Seoul National University Medical Research Center, 103 Daehak-ro, Jongno-gu, Seoul 03080, South Korea

Full list of author information is available at the end of the article
}

[1]. Medical Aid, along with National Health Insurance, is an important social security system that functions to protect people's health in Korea. However, despite its goal of solving the medical problems of low-income families, it is difficult to say whether the Medical Aid system is working adequately to that end. Compared to National Health Insurance beneficiaries, several studies have reported that Medical Aid beneficiaries had poor health status and received insufficient medical care. Medical Aid beneficiaries showed higher risks of chronic diseases [2, 3] and suicide [4], lower levels of medication adherence and continuity of treatment $[5,6]$, and lower effectiveness of behavioral intervention programs [7]. They also were more likely to receive lower-quality medical care

(c) The Author(s). 2019 Open Access This article is distributed under the terms of the Creative Commons Attribution 4.0 International License (http://creativecommons.org/licenses/by/4.0/), which permits unrestricted use, distribution, and reproduction in any medium, provided you give appropriate credit to the original author(s) and the source, provide a link to the Creative Commons license, and indicate if changes were made. The Creative Commons Public Domain Dedication waiver (http://creativecommons.org/publicdomain/zero/1.0/) applies to the data made available in this article, unless otherwise stated. 
[8-11], more vulnerable to environmental conditions $[12,13]$, and less likely to participate in national screening programs $[14,15]$. Consequently, Medical Aid beneficiaries have a higher risk of mortality than National Health Insurance beneficiaries [16]. As far as we are aware, however, no studies have compared life expectancy trends between Medical Aid beneficiaries and National Health Insurance beneficiaries in Korea. The purpose of this study was to estimate and compare life expectancy at birth among Medical Aid beneficiaries and National Health Insurance beneficiaries in Korea between 2004 and 2017 based on whole-population data from the National Health Insurance Service (NHIS).

\section{Methods}

Aggregate data on the numbers of population and deaths according to calendar year (2004 to 2017), sex, age groups $(0,1-4,5-9,10-11, \ldots, 85+)$, and eligibility (Medical Aid or National Health Insurance) were obtained from the National Health Information Database (NHID) provided by the NHIS in Korea [17]. The NHID data cover all Medical Aid beneficiaries and National Health Insurance beneficiaries in Korea except for foreigners. In this study, Medical Aid beneficiaries were defined as recipients of medical benefits as of the first day of the year based on the Medical Care Assistance Act. Medical Aid beneficiaries and National Health Insurance beneficiaries are mutually exclusive groups. National Health Insurance beneficiaries were Korean nationals who reside within the country, excluding those who receive medical benefits, based on National Health Insurance Act. Additional file 1: Table S1 presents the annual numbers of population and deaths according to eligibility during the study period. Between 2004 and 2017, a summed total of 697,503,634 subjects $(675,086,418$ National Health Insurance beneficiaries and 22,417,216 Medical Aid beneficiaries) and 3, 536,778 deaths $(3,037,174$ National Health Insurance beneficiaries and 499,604 Medical Aid beneficiaries) were analyzed (see Additional file 1: Table S1). The Medical Aid beneficiaries accounted for $2.8-3.7 \%$ of all Korean medical security beneficiaries during 20042017 (see Additional file 1: Figure S1).

Between 2004 and 2017, annual abridged life tables were constructed using 5-year probabilities of death separately for Medical Aid beneficiaries and National Health Insurance beneficiaries. Standard life table procedures were used to calculate survival rates [18], and the KannistoThatcher method was employed to expand the open-ended age interval of $85+$ to estimate the probability of dying for each of the 5-year age groups of 85-89, 90-94, ..., 120124 , and $125+$ [19]. In addition, an additional analysis was conducted to calculate the life expectancy and life expectancy differences according to the National Health Insurance type and eligibility (see Additional file 1: Table S2).

\section{Results}

Between 2004 and 2017, life expectancy increased for both National Health Insurance beneficiaries and Medical Aid beneficiaries, but the magnitude of the increase was greater for Medical Aid beneficiaries. During the 13year study period between 2004 and 2017, life expectancy for Medical Aid beneficiaries increased by 8.7 years in men and 6.1 years in women, respectively, while life expectancy for National Health Insurance beneficiaries increased by 5.2 years in men and 4.5 years in women (Table 1). Therefore, the life expectancy difference decreased from 15.4 years in 2004 to 12.8 years in 2017. The life expectancy difference between National Health Insurance beneficiaries and Medical Aid beneficiaries was larger in men than in women in all calendar years. The life expectancy difference ranged from 20.0 years to 15.8 years (average of 17.9 years during the study period) among men, while the gap ranged from 12.2 years to 8.9 years (average of 10.5 years during the study period) among women (Fig. 1, see Additional file 1: Table S3 for more detailed values). Women showed much higher life expectancies than men among both National Health Insurance beneficiaries and Medical Aid beneficiaries (Table 1). However, the sex difference in life expectancy was much greater among Medical Aid beneficiaries than among National Health Insurance beneficiaries. In 2017, the life expectancy difference between men and women was 12.6 years for Medical Aid beneficiaries, while the difference was 5.8 years for National Health Insurance beneficiaries (Table 1).

Table 1 Annual life expectancy among National Health Insurance (NHI) beneficiaries and Medical Aid beneficiaries between 2004 and 2017 by sex

\begin{tabular}{|c|c|c|c|c|c|c|}
\hline \multirow[t]{2}{*}{ Year } & \multicolumn{2}{|c|}{ Men and Women } & \multicolumn{2}{|l|}{ Men } & \multicolumn{2}{|c|}{ Women } \\
\hline & $\mathrm{NHI}$ & Medical Aid & $\mathrm{NHI}$ & Medical Aid & $\mathrm{NHI}$ & Medical Aid \\
\hline 2004 & 78.8 & 63.4 & 75.4 & 56.2 & 81.9 & 71.4 \\
\hline 2005 & 79.3 & 62.8 & 76.0 & 56.1 & 82.2 & 70.2 \\
\hline 2006 & 79.9 & 63.2 & 76.6 & 56.6 & 82.8 & 70.5 \\
\hline 2007 & 80.2 & 64.3 & 76.9 & 57.7 & 83.0 & 71.7 \\
\hline 2008 & 80.8 & 65.0 & 77.4 & 58.4 & 83.7 & 72.3 \\
\hline 2009 & 81.2 & 66.7 & 77.8 & 60.0 & 84.1 & 74.0 \\
\hline 2010 & 81.3 & 67.0 & 77.9 & 60.3 & 84.2 & 74.3 \\
\hline 2011 & 81.7 & 67.7 & 78.3 & 61.6 & 84.6 & 74.3 \\
\hline 2012 & 81.9 & 67.6 & 78.5 & 61.4 & 84.8 & 74.5 \\
\hline 2013 & 82.4 & 68.5 & 79.1 & 62.1 & 85.3 & 75.5 \\
\hline 2014 & 82.8 & 68.0 & 79.5 & 61.6 & 85.5 & 75.1 \\
\hline 2015 & 83.1 & 68.7 & 79.9 & 62.7 & 85.8 & 75.5 \\
\hline 2016 & 83.4 & 70.3 & 80.3 & 64.2 & 86.1 & 77.0 \\
\hline 2017 & 83.7 & 70.9 & 80.6 & 64.9 & 86.4 & 77.5 \\
\hline
\end{tabular}




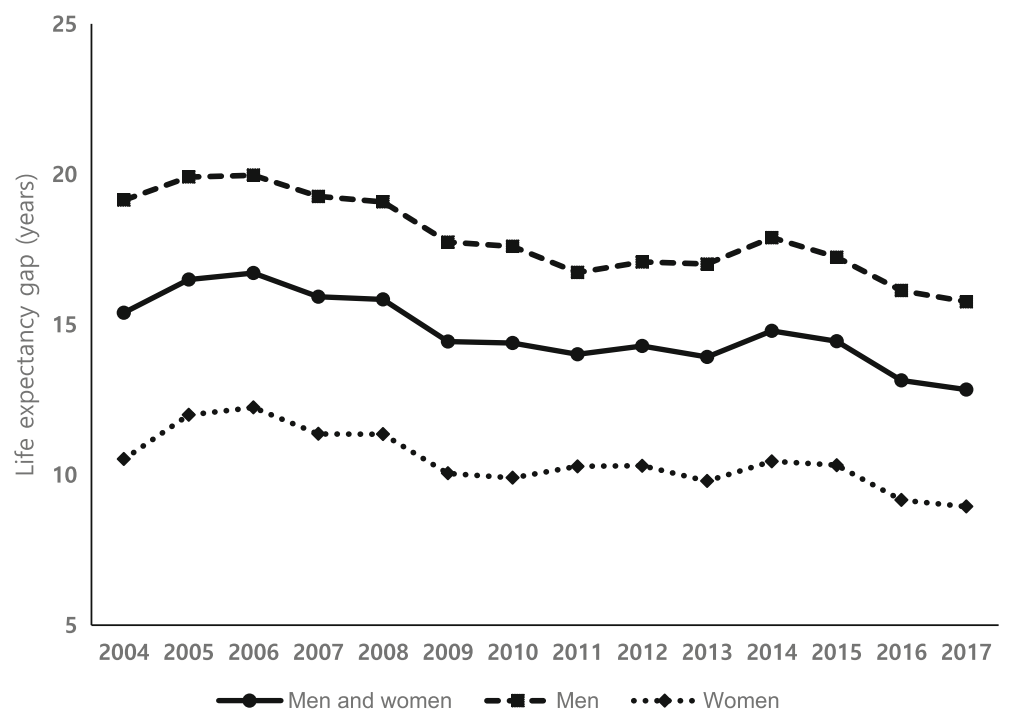

Fig. 1 Trends in life expectancy differences between National Health Insurance beneficiaries and Medical Aid beneficiaries by sex from 2004 to 2017

\section{Discussion}

The results of this study indicate that the life expectancy of Medical Aid beneficiaries was much shorter than that of National Health Insurance beneficiaries in Korea. The life expectancy gap was 15.8 years among men and 8.9 years among women in 2017. It is possible that poor health determines household poverty, especially among Medical Aid beneficiaries in Korea [20]. People who are not in good health may lose their job and then become poor, making them eligible to receive Medical Aid program benefits. However, it is also possible that other factors, such as socioeconomic disadvantages, discrimination, limited access to health care services, and lower quality of medical services might contribute to the lower life expectancy among Medical Aid beneficiaries than among National Health Insurance beneficiaries. These factors are suspected to create gaps between Medical Aid beneficiaries and National Health Insurance beneficiaries in all areas from prevention to treatment. For example, a smoking cessation program was less effective for Medical Aid beneficiaries and cessation rates were lower for Medical Aid beneficiaries than for National Health Insurance beneficiaries [7]. The participation rates in national screening programs, such as the National Screening Program for Transitional Ages or the National Cancer Screening Program, were lower among Medical Aid beneficiaries than among National Health Insurance beneficiaries [14, 15]. Compared to National Health Insurance beneficiaries, Medical Aid beneficiaries showed lower antihypertensive medication adherence and lower continuity of diabetes care [5, 6]. Medical Aid beneficiaries showed a higher acute appendicitis rupture rate than did National Health Insurance beneficiaries [8]. Among patients with schizophrenia, Medical Aid beneficiaries were less likely to use atypical drugs, which were recommended as the first-line treatment for schizophrenia, than National Health Insurance beneficiaries [9]. Medical Aid patients were more likely to discontinue lung cancer treatment than were high-income patients [10]. Medical Aid beneficiaries are economically and socially vulnerable, and therefore more likely to develop more serious conditions. The liver cancer risk in patients with liver disease was higher among Medical Aid beneficiaries than among National Health Insurance beneficiaries [2]. Medical Aid beneficiaries had a higher suicide rate than National Health Insurance beneficiaries [4]. In addition, the Medical Aid beneficiaries were more vulnerable to environmental conditions. The effect of heat and cold on hospital admissions for acute myocardial infarction and subarachnoid hemorrhage was greater in Medical Aid beneficiaries than in National Health Insurance beneficiaries [12, 13].

The results of this study showed that the gender gap of life expectancy was much greater in Medical Aid beneficiaries than in National Health Insurance beneficiaries, and this pattern was maintained between 2004 and 2017. The result that the sex difference in life expectancy was more prominent among Medical Aid beneficiaries could be partially explained by the alcohol consumption. Prior Korean study showed that alcoholrelated conditions such as alcoholic liver disease, suicide, transport accidents, and liver cancer were major contributors to gender differences of life expectancy inequalities by income [21].

In this study, the life expectancy difference between National Health Insurance beneficiaries and Medical Aid beneficiaries decreased over the study period. One possible 
explanation could be positive effects of the continuing revision of the Medical Care Assistance Act [22]. For example, in 2007, revisions of the Medical Care Assistance Act included a reduction of the support obligors who are responsible for supporting eligible recipients, a ban on deposits when a Medical Aid beneficiary is admitted, and providing priority when a Medical Aid beneficiary is injured. These reforms might have improved the health status of Medical Aid beneficiaries.

It should be noted that we found a similar pattern between the annual percentage of Medical Aid beneficiaries and trends in the life expectancy differences between National Health Insurance beneficiaries and Medical Aid beneficiaries (see Fig. 1 and Additional file 1: Figure S1). The size of recipients of Medical Aid beneficiaries varies from year to year (Additional file 1: Figure S1). The life expectancy differences between National Health Insurance beneficiaries and Medical Aid beneficiaries varies from year to year also (Fig. 1). The various patterns of the two figures are somewhat similar, although they were not perfectly matched. If this was not a coincidence, a potential explanation may relate to the health status of low-income groups not included as Medical Aid beneficiaries. The life expectancy difference was high when the percentage of Medical Aid beneficiaries was high. This might have been because people who were more vulnerable in terms of health risks than National Health Insurance beneficiaries (for example, the second-lowest income bracket) were not fully eligible to receive Medical Aid program benefits, even though their health needs were urgent. This possibility should be examined in a future study exploring the health status of low-income groups who are not Medical Aid beneficiaries. Several US studies have shown positive effects of state Medicaid expansions on mortality reduction, including infant mortality, especially among disadvantaged populations [23-25].

A limitation of this study is that we were not able to distinguish the type of medical benefits, despite the possibility that there might have been differences in mortality patterns between Medical Aid type 1 (for those being incapable of working) and Medical Aid type 2 (for those being capable of working). However, so far as we are aware, this is the first report of life expectancy at birth and its time trends in Medical Aid beneficiaries compared to National Health Insurance beneficiaries using whole-population data in Korea.

\section{Conclusions}

In conclusion, this study showed that Medical Aid beneficiaries had a much lower life expectancy than National Health Insurance beneficiaries between 2004 and 2017. The government should implement more effective policies to reduce these life expectancy differences and to protect the health of Medical Aid beneficiaries.

\section{Additional file}

Additional file 1: Figure S1. Annual numbers and percentage of Medical Aid beneficiaries, as of the end of the year, in Korea from 2004 to 2017 (data from Medical Aid statistics by National Health Insurance Service). Table S1. Number of population (as of the first day of the year) and deaths according to eligibility. Table S2. Life expectancy and life expectancy differences according to type of insurance and eligibility by sex. Table S3. Life expectancy differences between National Health Insurance beneficiaries and Medical Aid beneficiaries by sex. (DOCX 97 kb)

\section{Abbreviations}

NHID: National Health Information Database; NHIS: National Health Insurance Service

\section{Acknowledgements}

We thank Dr. Yeon-Yong Kim and Dr. Jong Heon Park at the National Health Insurance Service of Korea for supporting this research.

\section{Authors' contributions}

YK designed the study and HK collected the data. JB performed the statistical analysis. YK, JB, and HK drafted and critically revised the manuscript. All authors read and approved the final paper.

\section{Funding}

This research was supported by a grant of the Korea Health Technology R\&D Project through the Korea Health Industry Development Institute (KHIDI), funded by the Ministry of Health \& Welfare, Republic of Korea (grant number: HI18C0446). The funding body did not have any role in the design of the study and collection, analysis, and interpretation of data and in writing the manuscript.

\section{Availability of data and materials}

The data that support the findings of this study are available from the National Health Insurance Service in Korea but restrictions apply to the availability of these data, which were used under license for the current study, and so are not publicly available. Data are however available from the authors upon reasonable request and with permission of the National Health Insurance Service in Korea.

\section{Ethics approval and consent to participate}

This study was approved by the National Health Insurance Service of Korea (No. NHIS-2019-1-205) and the Seoul National University Hospital Institutional Review Board (IRB No. E-1810-008-975).

\section{Consent for publication}

Not applicable

\section{Competing interests}

The authors declare that they have no competing interests.

\section{Author details}

1Department of Public Health, Keimyung University, 1095, Dalgubeol-daero, Dalseo-gu, Daegu 42601, South Korea. ${ }^{2}$ Department of Health Policy and Management, Seoul National University College of Medicine, 103 Daehak-ro, Jongno-gu, Seoul 03080, South Korea. ${ }^{3}$ Institute of Health Policy and Management, Seoul National University Medical Research Center, 103 Daehak-ro, Jongno-gu, Seoul 03080, South Korea.

Received: 29 April 2019 Accepted: 14 August 2019 Published online: 19 August 2019

\section{References}

1. National Health Insurance Service, Health insurance review \& assessment service: 2017 medical aid statistics Wonju: National Health Insurance Service, Health Insurance Review \& Assessment Service, 2018.

2. Suh JK, Lee J, Lee JH, Shin S, Tchoe HJ, Kwon JW. Risk factors for developing liver cancer in people with and without liver disease. PLoS One. 2018;13: e0206374. 
3. Kim EJ, Yoon SJ, Jo MW, Kim HJ. Measuring the burden of chronic diseases in Korea in 2007. Public Health. 2013;127:806-13.

4. Lee SU, Oh $\mathrm{HH}_{\text {, Jeon } \mathrm{HJ}}$, Roh S. Suicide rates across income levels: retrospective cohort data on 1 million participants collected between 2003 and 2013 in South Korea. J Epidemiol. 2017;27:258-64.

5. Shin S, Song H, Oh SK, Choi KE, Kim H, Jang S. Effect of antihypertensive medication adherence on hospitalization for cardiovascular disease and mortality in hypertensive patients. Hypertens Res. 2013;36:1000-5.

6. Yoon CH, Lee SJ, Choo S, Moon OR, Park JH. Continuity of care of patient with diabetes and its affecting factors in Korea. J Prev Med Public Health. 2007:40:51-8.

7. Kim H, Oh JK, Lim MK, Jeong BY, Yun EH, Park EY. The national "smoking cessation clinics" program in the republic of Korea: socioeconomic status and age matter. Asian Pac J Cancer Prev. 2013;14:6919-24.

8. Na BJ, Hong JY, Kim KY, Lee MS, Nam HS, Im JS, Rhee JA. The relation between type of insurance and acute appendicitis rupture rate. J Prev Med Public Health. 2004;37:267-73.

9. Lee SU, Ryu V, Soh M, Kim CE, Park S, Roh S, Oh IH, Lee HY, Choi S. Changes in antipsychotic drug usage and factors affecting the use of typical drugs based on nationwide health insurance data in South Korea. BMJ Open. 2018:8:e020280.

10. Choi WI, Choi J, Kim MA, Lee G, Jeong J, Lee CW. Higher age puts lungCancer patients at risk for not receiving anti-cancer treatment. Cancer Res Treat. 2018.

11. Kim Y, Oh J, Jha A. Contribution of hospital mortality variations to socioeconomic disparities in in-hospital mortality. BMJ Qual Saf. 2014;23: $741-8$.

12. Kwon BY, Lee E, Lee S, Heo S, Jo K, Kim J, Park MS. Vulnerabilities to temperature effects on acute myocardial infarction hospital admissions in South Korea. Int J Environ Res Public Health. 2015;12:14571-88.

13. Lee S, Guth M. Associations between temperature and hospital admissions for subarachnoid hemorrhage in Korea. Int J Environ Res Public Health. 2017;14.

14. Kim HS, Shin DW, Lee WC, Kim YT, Cho B. National screening program for transitional ages in Korea: a new screening for strengthening primary prevention and follow-up care. J Korean Med Sci. 2012;27(Suppl):S70-5.

15. Sung NY, Park EC, Shin HR, Choi KS. participation rate and related sociodemographic factors in the national cancer screening program. J Prev Med Public Health. 2005;38:93-100.

16. Jang SI, Yi SW, Sull JW, Park EC, Kim JH, Ohrr H. Association between allcause mortality and insurance status transition among the elderly population in a rural area in Korea: Kangwha cohort study. Health Policy. 2015;119:680-7.

17. Seong SC, Kim YY, Khang YH, Heon Park J, Kang HJ, Lee H, Do CH, Song JS, Hyon Bang J, Ha S, et al. Data resource profile: the National Health Information Database of the National Health Insurance Service in South Korea. Int J Epidemiol. 2017:46:799-800.

18. Preston $S$, Heuveline $P$, Guillot M. Demography: measuring and modeling population processes: Wiley-Blackwell; 2000

19. Thatcher AR, Vi K, Vaupel JW. The force of mortality at ages 80 to 120 . Odense: Odense University Press; 1998.

20. Kim J, Yang BM, Lee TJ, Kang E. A causality between health and poverty: an empirical analysis and policy implications in the Korean society. Soc Work Public Health. 2010;25:210-22.

21. Khang YH, Bahk J, Yi N, Yun SC. Age- and cause-specific contributions to income difference in life expectancy at birth: findings from nationally representative data on one million south Koreans. Eur J Pub Health. 2016;26: 242-8.

22. Shin Y. Direction to go for medical aid. Health and welfare policy forum. 2010;167:28-38

23. Bhatt CB, Beck-Sague CM. Medicaid expansion and infant mortality in the United States. Am J Public Health. 2018:108:565-7.

24. Sommers BD, Baicker K, Epstein AM. Mortality and access to care among adults after state Medicaid expansions. N Engl J Med. 2012;367:1025-34.

25. Sommers BD, Long SK, Baicker K. Changes in mortality after Massachusetts health care reform: a quasi-experimental study. Ann Intern Med. 2014;160: 585-93.

\section{Publisher's Note}

Springer Nature remains neutral with regard to jurisdictional claims in published maps and institutional affiliations.

\section{Ready to submit your research? Choose BMC and benefit from:}

- fast, convenient online submission

- thorough peer review by experienced researchers in your field

- rapid publication on acceptance

- support for research data, including large and complex data types

- gold Open Access which fosters wider collaboration and increased citations

- maximum visibility for your research: over $100 \mathrm{M}$ website views per year

At $\mathrm{BMC}$, research is always in progress.

Learn more biomedcentral.com/submissions 